\title{
The effect of low and moderate fat intakes on the postprandial lipaemic and hormonal responses in healthy volunteers
}

\author{
Farideh Shishehbor, Helen M. Roche and Michael J. Gibney* \\ Unit of Nutrition and Dietetics, Department of Clinical Medicine, Trinity Centre for Health Sciences, \\ St James's Hospital, Dublin 8, Republic of Ireland
}

(Received 2 March 1998 - Revised 6 July 1998 - Accepted 9 July 1998)

\begin{abstract}
Present literature indicates that whereas an acute fat intake of $5 \mathrm{~g}$ does not elicit a postprandial triacylglycerolaemic response, $20 \mathrm{~g}$ of fat does. Since $67 \%$ of fat intake occasions involve fat doses of less than $20 \mathrm{~g}$, the present study examined the effect of a relatively low-fat (LF) meal $(0 \cdot 2 \mathrm{~g} / \mathrm{kg}$ body weight; mean $14 \mathrm{~g})$ on postprandial triacylglycerol (TAG) metabolism, compared with a high-fat (HF) meal $(0.6 \mathrm{~g} / \mathrm{kg}$ body weight; mean $43 \mathrm{~g})$, a fat dose which is more typical of laboratory studies. Plasma- and chylomicron-TAG concentrations increased significantly $(P \leq 0.001)$ following both meals, and the increase was significantly $(P \leq 0.02)$ greater after the HF meal. The postprandial areas under the curves and maximal postprandial TAG concentrations for plasma- and chylomicron-TAG were significantly higher following the HF meal $(P \leq 0.05)$. Postprandial plasma insulin and gastric inhibitory polypeptide concentrations increased significantly $(P \leq 0.001)$ after each meal, but there was no difference between the two meals. These data show that modest amounts of fat in a meal will elicit a measurable postprandial TAG response. Since postprandial lipaemia affects the composition and concentration of the TAG- and cholesterol-rich lipoproteins, controlling dietary TAG supply may influence the metabolic fate of these lipoproteins.
\end{abstract}

Postprandial lipaemia: Triacylglycerols: Dietary fat

The acute effect of fat ingestion on the postprandial lipaemic response has been extensively investigated. The amount of fat used in test meals, in general, has varied between 40 and $100 \mathrm{~g}$ (Redgrave \& Carlson, 1979; Groot \& Scheek, 1984; Cohen et al. 1988; Cohn et al. 1988a; Bonanome \& Grundy, 1989; Krasinski et al. 1990; Rifai et al. 1990; Zampelas et al. 1994a,b; Roche \& Gibney, 1996). However, a recent study in this laboratory (K Harrington, personal communication) of 106 free-living healthy adult males, observed over a $7 \mathrm{~d}$ period involving more than 3000 eating occasions, has shown that on $26 \%$ of occasions fat ingestion is below $5 \mathrm{~g}$, on $41 \%$ of occasions fat ingestion is between 5 and $20 \mathrm{~g}$ and on only $33 \%$ of occasions is fat intake above $20 \mathrm{~g}$. De Castro (1987) has also reported data which reveal that most eating occasions involve fat intakes of between 12 and $30 \mathrm{~g}$. In planning a study of the effect of moderate fat intakes on the postprandial lipaemic response, note was taken of the literature prevailing at that time.

Cohen et al. (1988) showed that the magnitude of postprandial lipaemia was directly related to fat ingestion in studies involving doses of 40, 80 and $120 \mathrm{~g}$ fat. Dubois et al. (1994) found significant differences in postprandial lipaemia with doses of 31 and $43 \mathrm{~g}$ fat. Chen et al. (1992) examined the postprandial triacylglycerol (TAG) response in subjects with non-insulin dependent diabetes mellitus with doses of fat to provide either $25 \%$ or $45 \%$ of dietary energy. More recent publications have used doses as low as $5 \mathrm{~g}$ compared with doses of 40 or $80 \mathrm{~g}$ fat (Jeppesen et al. 1995) and doses from 20 to $80 \mathrm{~g}$ fat (Murphy et al. 1995). Since the completion of the present study, Dubois et al. $(1998)$ have extended this area to examine the effects of 0 , $15,30,40$ and $50 \mathrm{~g}$ fat where the lowest fat dose $(15 \mathrm{~g})$ elicited a small increase in postprandial plasma TAG concentrations. Previous work in this laboratory has shown that $11 \mathrm{~g}$ fat can elicit a postprandial TAG response of sufficient magnitude to stimulate reverse cholesterol transport (O'Flaherty \& Gibney, 1994). Clearly, a need exists to clarify the capacity of lower doses of fat to elicit a postprandial lipaemic response, given that some $67 \%$ of eating occasions involve fat intakes of less than $20 \mathrm{~g}$.

Murphy et al. (1995) showed that doses of $20 \mathrm{~g}$ fat were capable of eliciting a plasma gastric inhibitory polypeptide (GIP) response. GIP augments insulin-mediated stimulation of lipoprotein lipase ( $E C$ 3.1.1.34), the enzyme that

\footnotetext{
Abbreviations: AUC, area under the curve; $\mathrm{CM}$, chylomicron; $\mathrm{C}_{\mathrm{MAX}}$, maximum postprandial concentration; GIP, gastric inhibitory polypeptide; HF, high fat; LF, low fat; NEFA, non-esterified fatty acid; TAG, triacylglycerol.

* Corresponding author: Professor Michael Gibney, fax +353 1454 2043, email mgibney@tcd.ie
} 
catalyses plasma TAG clearance. Therefore the postprandial responses of insulin and GIP, as well as plasma lipid concentrations were investigated in the present study. The low and high fat doses $(0.2$ and $0.6 \mathrm{~g}$ fat $/ \mathrm{kg}$ body weight $)$ yielded mean acute intakes of $14 \mathrm{~g}$ for the low-fat (LF) meal and $43 \mathrm{~g}$ for the high-fat (HF) meal. This represents the range of fat intakes which are commonly consumed on a single eating occasion.

\section{Experimental methods}

\section{Study design}

This study was approved by the Ethics Committee of the Federated Dublin Voluntary Hospitals. Eight healthy subjects, four male and four female, participated in the study. None was taking any medication or nutritional supplements which would interfere with lipid metabolism. The subjects' mean age was 28.4 (range 22-36) years and the mean BMI was $24 \cdot 1$ (range 19.9-27.2) $\mathrm{kg} / \mathrm{m}^{2}$. Subjects refrained from drinking alcohol and taking strenuous exercise for $24 \mathrm{~h}$ before each postprandial investigation and avoided smoking during these investigations. They took a light dinner on the evening before the studies and reported to the laboratory between 08.00 and 09.00 hours, following a $12 \mathrm{~h}$ overnight fast. A 21 gauge, $32 \mathrm{~mm}$ venous cannula catheter (Abbot Ireland Ltd, Dublin, Republic of Ireland) was inserted into the antecubital vein of the forearm and a fasting sample was collected. Following meal ingestion, blood samples were drawn at 2, 4, 6 and $8 \mathrm{~h}$ for lipid analysis and additionally at 3,5 and $7 \mathrm{~h}$ for insulin and GIP analysis. Blood was drawn into vacutainer tubes (containing $0.12 \mathrm{ml} 0.3 \mathrm{M}$-EDTA $\mathrm{K}_{3}$ ). After each blood sample was taken the cannula was rinsed with $1 \mathrm{ml}$ normal saline and the first $10 \mathrm{ml}$ blood drawn at each sampling time point was discarded.

\section{Test meal composition}

The test meals were liquid blends of skimmed milk and soyabean oil. The LF meal provided $0 \cdot 2 \mathrm{~g}$ fat, $0 \cdot 2 \mathrm{~g}$ carbohydrate and $0.18 \mathrm{~g}$ protein per $\mathrm{kg}$ body weight while the HF meal contained $0.6 \mathrm{~g}$ fat, $0.2 \mathrm{~g}$ carbohydrate and $0.18 \mathrm{~g}$ protein per $\mathrm{kg}$ body weight. Because of variation in body weight, the range of fat intakes for the LF meal was 10-18 g (mean $14 \mathrm{~g}$ ) while for the HF diet it was 31-56 g (mean $43 \mathrm{~g}$ ). The average energy intake was $979 \mathrm{~kJ}$ for the LF meal and $2051 \mathrm{~kJ}$ for the HF meal.

\section{Biochemical analysis}

Plasma samples were immediately centrifuged at 2500 rev./ min for $15 \mathrm{~min}$, the plasma was harvested, divided into portions and frozen $\left(-20^{\circ}\right)$ immediately for subsequent analysis. Plasma for chylomicron (CM) separation was stored overnight $\left(2-5^{\circ}\right)$. The plasma $\mathrm{CM}$ fraction was separated using the method of Grundy \& Mok (1976) with some modification, as previously described (Roche et al. 1998). In a $4.7 \mathrm{ml}$ Optiseal polyallomer centrifuge tube (Beckman Instruments Inc., Palo Alto, CA, USA), $2.35 \mathrm{ml}$ plasma was overlaid with $2.35 \mathrm{ml}$ saline $(\rho=1.006 \mathrm{~g} / \mathrm{ml})$. The CM fraction was isolated by ultracentrifugation $(100000 \mathrm{rev} . / \mathrm{min}$ for $24 \mathrm{~min}(5.29 \times$ $10^{6}$ g.min), at $4^{\circ}$ ) (Beckman Optima TLX ultracentrifuge with a TLA 100.4 rotor, Beckman Instruments Inc.). The CM fraction was harvested and stored $\left(-20^{\circ}\right)$ for subsequent analysis.

Enzymic colorimetric assays were used to determine plasma TAG, CM-TAG (PAP 500; Biomerieux, France) and plasma non-esterified fatty acid (NEFA) (NEFAC; Wako Chemical GmbH, Neuss, Germany) concentrations. Plasma insulin concentrations were measured by radioimmunoassay (Kabi Pharmacia (Ireland) Ltd, Dublin, Republic of Ireland). Plasma GIP was measured by radioimmunoassay (Alam et al. 1992); this analysis was kindly carried out by Professor K. Buchanan (Wellcome Research Laboratories, Royal Victoria Hospital, Belfast, UK).

Data were analysed by repeated measures ANOVA using Data Desk 4.1 (Data Description Inc., Ithaca, NY, USA). The repeated measures model was designed to investigate the effect of several independent variables, including subject, sex, meal and time, on the postprandial response. All the data, with the exception of plasma NEFA, were transformed to their natural $\log$ to render their distribution normal. The NEFA data were transformed using the square root to normalize their distribution. Summary postprandial variables of the postprandial response including the area under the curve (AUC) (Mathews et al. 1990), the incremental AUC, maximum postprandial concentrations $\left(\mathrm{C}_{\mathrm{MAX}}\right)$ and time to $\mathrm{C}_{\mathrm{MAX}}$, were analysed by ANOVA. Multiple regression analysis was used to explore factors influencing GIP AUC.

\section{Results}

Postprandial plasma TAG, CM-TAG and NEFA values are presented in Table 1 . The concentrations of TAG in plasma and the CM fraction were significantly $(P \leq 0.0001)$ increased during the postprandial response phase. There were significantly greater increases in plasma- and CMTAG concentrations $(P=0.01$ and $P=0.02$ respectively $)$ following the $\mathrm{HF}$ meal; the post-hoc least significance difference test showed that this difference between meals occurred at 4 and $6 \mathrm{~h}(P \leq 0 \cdot 05)$. Postprandial plasma NEFA concentrations were significantly $(P \leq 0.0001)$ reduced during the postprandial phase, but there was no difference between meals. The repeated measures model took account of the sex mix in the study design; there was no significant effect of sex on plasma TAG or NEFA concentrations. CM-TAG concentrations were significantly $(P=0.03)$ greater in the men; however, there was no sex $\times$ meal interaction, which demonstrates that sex did not influence the difference seen between meals.

The plasma insulin and GIP responses are presented in Table 2. The concentrations of both variables increased significantly during the postprandial response phase $(P=0.0001$ and $P=0.0003$ respectively), but there was no significant difference between meals. Sex had no effect on either of these variables. The summary variables of the postprandial response (AUC, incremental AUC, $\mathrm{C}_{\mathrm{MAX}}$ and time to $\mathrm{C}_{\mathrm{MAX}}$ ) are presented in Table 3 . The postprandial plasma TAG AUC, incremental AUC and $\mathrm{C}_{\mathrm{MAX}}$ 
Table 1. Postprandial plasma triacylglycerol (TAG), chylomicron-TAG (CM-TAG) and non-esterified fatty acid (NEFA) responses to the ingestion of a high-fat (HF) or low-fat (LF) test meals by healthy volunteers $\ddagger$

(Mean values and standard deviations for eight subjects)

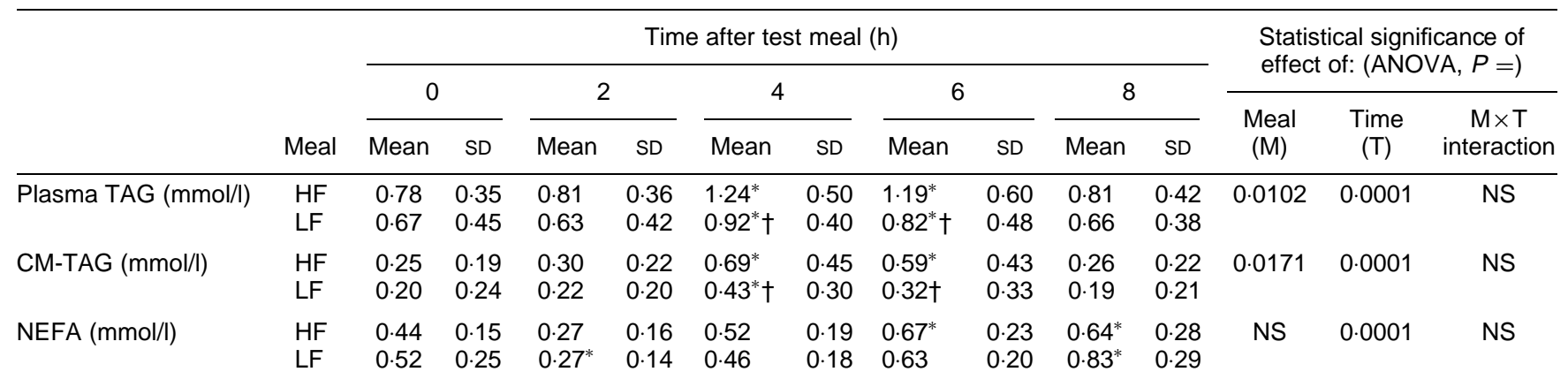

Mean values were significantly different from fasting values, ${ }^{*} P<0.05$.

Mean values were significantly different from those for the HF meal, $\dagger P<0.05$

$\ddagger$ For details of meals and procedures, see p. 26.

values were significantly greater following the $\mathrm{HF}$ meal than after the LF meal $(P=0.03, P=0.05$ and $P=0.02$ respectively). Sex had no effect on the summary variables for the postprandial plasma TAG response. The CM-TAG AUC and $\mathrm{C}_{\mathrm{MAX}}$ were significantly greater following the $\mathrm{HF}$ meal than after the LF meal $(P=0.03$ and $P=0.01$ respectively). For both of these variables CM-TAG levels were greater in males than in females, but these differences did not reach statistical significance $(P \geq 0.06)$, and there was no sex $\times$ meal interaction which demonstrates that sex did not influence the difference between meals. The summary variables of the postprandial GIP and insulin responses were not significantly different between meals.

In the case of GIP, it was clear that there was a tendency toward a higher and more prolonged response after the $\mathrm{HF}$ meal and given the large between-subject variation for this variable, a regression analysis was completed to examine the determinants of GIP AUC (Table 4). Fasting plasma GIP concentrations (GIP-0) explained $39 \%$ of the GIP AUC variation $\left(r^{2} 0 \cdot 39, P=0 \cdot 0076\right)$. When 'subject' was included in the model the strength of the equation increased substantially $\left(r^{2} 0.756, P<0.0001\right.$ for GIP-0 and $P=0.007$ for subject). CM-TAG AUC had a significant, albeit minor, influence on the regression equation $\left(r^{2} 0.828, P=0.0015\right.$ for GIP-0; $P=0.0004$ for subject; $P=0.0325$ for CM-TAG AUC). The effects of several other variables were investigated but these three were the important factors determining the postprandial plasma GIP AUC.

\section{Discussion}

The results of the present study show that a dose of fat more akin to the normal level of fat consumed on a single eating occasion in free-living subjects, elicits a small but

Table 2. Postprandial insulin and gastric inhibitory polypeptide (GIP) responses to the ingestion of a high-fat (HF) or low-fat (LF) test meals by healthy volunteers $\dagger$

(Mean values and standard deviations for eight subjects)

\begin{tabular}{|c|c|c|c|c|c|c|c|c|}
\hline \multirow[b]{3}{*}{ Time after test meal (h) } & \multicolumn{4}{|c|}{ Insulin $(\mu \mathrm{U} / \mathrm{ml})$} & \multicolumn{4}{|c|}{$\mathrm{GIP}(\mathrm{ng} / \mathrm{l})$} \\
\hline & \multicolumn{2}{|c|}{$\mathrm{HF}$} & \multicolumn{2}{|c|}{ LF } & \multicolumn{2}{|c|}{$\mathrm{HF}$} & \multicolumn{2}{|c|}{ LF } \\
\hline & Mean & SD & Mean & SD & Mean & SD & Mean & SD \\
\hline 0 & 8.62 & 3.78 & 8.56 & 1.67 & 19.4 & 8.6 & $18 \cdot 1$ & 7.5 \\
\hline 1 & $12 \cdot 10^{*}$ & $7 \cdot 27$ & $11.75^{*}$ & 5.0 & 30.6 & $15 \cdot 0$ & 27.5 & 9.3 \\
\hline 2 & 8.64 & $2 \cdot 66$ & $8 \cdot 38$ & $2 \cdot 19$ & $36 \cdot 3^{*}$ & $21 \cdot 0$ & 28.8 & 11.9 \\
\hline 3 & 8.91 & 4.52 & 6.85 & 1.88 & $49 \cdot 4^{*}$ & $40 \cdot 1$ & $34 \cdot 3^{*}$ & $13 \cdot 7$ \\
\hline 4 & 6.94 & 1.60 & $6 \cdot 26^{*}$ & 1.72 & $34.4^{*}$ & $18 \cdot 8$ & $38.8^{*}$ & $16 \cdot 6$ \\
\hline 5 & $6 \cdot 27^{*}$ & $2 \cdot 65$ & $5 \cdot 38^{*}$ & $1 \cdot 16$ & $43 \cdot 8^{*}$ & 39.4 & $26 \cdot 4$ & $12 \cdot 2$ \\
\hline 6 & $6 \cdot 47$ & $2 \cdot 51$ & $4.86 *$ & 1.84 & $38.8^{*}$ & $30 \cdot 6$ & $23 \cdot 1$ & $10 \cdot 0$ \\
\hline 7 & $4.95^{*}$ & 1.73 & $5 \cdot 10^{*}$ & 1.22 & $31 \cdot 3$ & $13 \cdot 0$ & 28.8 & $15 \cdot 1$ \\
\hline 8 & $4 \cdot 79^{*}$ & $1 \cdot 70$ & $5 \cdot 48^{*}$ & $1 \cdot 70$ & $25 \cdot 6$ & $10 \cdot 8$ & $23 \cdot 1$ & 8.4 \\
\hline \multicolumn{9}{|l|}{$\begin{array}{l}\text { Statistical significance } \\
\text { of effect of: (repeated } \\
\text { measures ANOVA, } P=\text { ) }\end{array}$} \\
\hline Meal (M) & \multicolumn{4}{|c|}{ NS } & \multicolumn{4}{|c|}{ NS } \\
\hline Time $(T)$ & \multicolumn{4}{|c|}{0.0001} & \multicolumn{4}{|c|}{0.0003} \\
\hline $\mathrm{M} \times \mathrm{T}$ interaction & \multicolumn{4}{|c|}{ NS } & \multicolumn{4}{|c|}{ NS } \\
\hline
\end{tabular}

Mean values were significantly different from fasting values, ${ }^{*} P<0.05$.

†For details of meals and procedures, see p. 26. 
Table 3. Summary postprandial data for plasma triacylglycerols (TAG), chylomicron-TAG (CM-TAG), insulin and gastric inhibitory polypeptide (GIP) following ingestion of high-fat (HF) and low-fat (LF) test meals by healthy volunteers $\dagger$

(Mean values and standard deviations for eight subjects)

\begin{tabular}{|c|c|c|c|c|c|c|c|c|c|}
\hline & Meal & \multicolumn{4}{|c|}{ Area under the curve } & \multicolumn{2}{|c|}{$\begin{array}{l}\text { Time to maximum } \\
\text { observed value } \\
\text { (h) }\end{array}$} & \multicolumn{2}{|c|}{$\begin{array}{l}\text { Maximum } \\
\text { observed value } \\
\text { (units) }\end{array}$} \\
\hline Plasma TAG (mmol/l) & $\begin{array}{l}\mathrm{HF} \\
\mathrm{LF}\end{array}$ & $\begin{array}{l}8.07^{*} \\
6.07\end{array}$ & $\begin{array}{l}3.46 \\
3.37\end{array}$ & $\begin{array}{l}1.84^{*} \\
0.73\end{array}$ & $\begin{array}{l}1.23 \\
0.46\end{array}$ & $\begin{array}{l}4.50 \\
4.75\end{array}$ & $\begin{array}{l}0.93 \\
1.04\end{array}$ & $\begin{array}{l}1.37^{*} \\
0.94\end{array}$ & $\begin{array}{l}0.57 \\
0.41\end{array}$ \\
\hline CM-TAG $(\mathrm{mmol} / \mathrm{l})$ & $\begin{array}{l}\mathrm{HF} \\
\mathrm{LF}\end{array}$ & $\begin{array}{l}3 \cdot 67^{*} \\
2 \cdot 32\end{array}$ & $\begin{array}{l}2.44 \\
2 \cdot 06\end{array}$ & $\begin{array}{l}1.66 \\
0.69\end{array}$ & $\begin{array}{l}1 \cdot 31 \\
0 \cdot 45\end{array}$ & $\begin{array}{l}4.50 \\
4.00\end{array}$ & $\begin{array}{l}0.93 \\
1.07\end{array}$ & $\begin{array}{l}0.78^{*} \\
0.44\end{array}$ & $\begin{array}{l}0.46 \\
0.30\end{array}$ \\
\hline Insulin $(\mu \mathrm{U} / \mathrm{ml})$ & $\begin{array}{l}\text { HF } \\
\text { LF }\end{array}$ & $\begin{array}{l}61 \\
56\end{array}$ & $\begin{array}{l}23 \\
10\end{array}$ & $\begin{array}{l}53 \\
43\end{array}$ & $\begin{array}{l}26 \\
22\end{array}$ & $\begin{array}{l}1.75 \\
1.63\end{array}$ & $\begin{array}{l}0.89 \\
1.06\end{array}$ & $\begin{array}{l}12 \cdot 8 \\
12 \cdot 2\end{array}$ & $\begin{array}{l}6 \cdot 7 \\
4 \cdot 7\end{array}$ \\
\hline GIP (ng/l) & $\begin{array}{l}\text { HF } \\
\text { LF }\end{array}$ & $\begin{array}{l}287 \\
221\end{array}$ & $\begin{array}{r}159 \\
67\end{array}$ & $\begin{array}{l}419 \\
296\end{array}$ & $\begin{array}{l}275 \\
108\end{array}$ & $\begin{array}{l}2.75 \\
3.00\end{array}$ & $\begin{array}{l}1.39 \\
1.07\end{array}$ & $\begin{array}{l}58 \\
44\end{array}$ & $\begin{array}{l}38 \\
15\end{array}$ \\
\hline
\end{tabular}

Mean values were significantly different from those for the LF meal, ${ }^{*} P<0.05$. †For details of meals and procedures, see p. 26.

significant rise in postprandial TAG level. At the outset of this study, the prevailing literature showed that $5 \mathrm{~g}$ fat did not elicit a significant lipaemic response (Jeppesen et al. 1995), but that a dose of $20 \mathrm{~g}$ fat did (Murphy et al. 1995). In the present study, fat intakes of $14-15 \mathrm{~g}$ significantly increased plasma TAG concentrations, although the postprandial response was small and short-lived. Recently, Dubois et al. (1998) examined the postprandial TAG response to a fat-free meal and to meals containing 15,30 , 40 and $50 \mathrm{~g}$ fat. The $15 \mathrm{~g}$ fat dose elicited a modest but significant rise in CM-TAG $2 \mathrm{~h}$ after the meal, although the AUC for the postprandial CM-TAG response was not significantly increased, whereas the greater fat doses $(30,40$ and $50 \mathrm{~g}$ ) significantly increased the postprandial CM-TAG AUC, in a dose-dependent fashion. This research group previously reported that modest differences in fat intake ( $31 \mathrm{~g}$ and $42 \mathrm{~g}$ ) significantly influenced postprandial triacylglycerolaemia (Dubois et al. 1994). However, in contrast, Murphy et al. (1995) found no significant difference in plasma TAG response between intakes of $20 \mathrm{~g}$ and $40 \mathrm{~g}$ fat but did observe a significantly higher postprandial TAG response when $80 \mathrm{~g}$ fat was used. These contrasting findings probably reflect different experimental conditions between the studies.

Table 4. Multiple regression modelling of the area under the plasma gastric inhibitory polypeptide (GIP) curve (GIP AUC) and the effects of fasting GIP levels (GIP-0), subject, fat intake (g) and the area under the chylomicron-triacylglycerol curve (CM-TAG AUC) in postprandial data from eight subjects

\begin{tabular}{lcc}
\hline $\begin{array}{l}\text { Dependent variable = GIP AUC } \\
\text { Independent variables }\end{array}$ & $P=$ & $r^{2}$ adjusted \\
\hline (i) GIP-0 & 0.0076 & $39.0(F$ 9.96) \\
(ii) GIP-0 & $<0.0001$ & $75.6(F$ 22.7) \\
Subject & 0.007 & \\
(iii) GIP-0 & 0.0015 & $82.8(F$ 23.4) \\
Subject & 0.0004 & \\
CM-TAG AUC & 0.0325 &
\end{tabular}

Dubois et al. (1998) demonstrated that the incremental increase in the AUC for serum TAG per unit weight of fat ingested following meals containing 30, 40 and $50 \mathrm{~g}$ was constant (0.090, 0.089 and 0.091 mmol.h/1 respectively) and much greater than that following a meal containing $15 \mathrm{~g}$ fat $(0.043 \mathrm{mmol} . \mathrm{h} / \mathrm{l})$. Therefore the TAG-clearing capacity of the normolipaemic subjects was not exceeded by the $15 \mathrm{~g}$ fat meal but it was exceeded by the higher fat meals, in proportion to the amount of fat ingested. Postprandial lipaemia not only represents the flux of dietary TAG within the circulation, but it is a key metabolic event which determines the composition and metabolic fate of HDL and LDL (Roche \& Gibney, 1995). In coronary artery disease, the preponderance of small dense LDL particles and low HDL-cholesterol concentrations are all associated with an elevated postprandial TAG response, whereas an attenuated response has beneficial effects, such as reverse cholesterol transport (O'Flaherty \& Gibney, 1994). Dubois et al. (1998) showed that although $15 \mathrm{~g}$ fat caused relatively unimportant changes in postprandial TAG concentrations, this fat dose was capable of affecting the composition and concentration of HDL and LDL. The present study supports the finding that $14-15 \mathrm{~g}$ fat can stimulate a postprandial lipaemic response. Therefore controlling dietary TAG not only determines the magnitude of the postprandial TAG response, but it can be associated with the beneficial effects on LDL and HDL metabolism, such as reverse cholesterol transport.

Sex has been shown to affect the magnitude of the postprandial response, that is, peak postprandial TAG concentrations were greater in males than females (Kashyap et al. 1983; Cohn et al. 1988b). However, in those studies fasting plasma TAG levels were also greater in the male subjects. Since fasting TAG concentration is a strong predictor of the magnitude of the postprandial response, this may explain the greater postprandial TAG concentrations. Alternatively the difference in postprandial TAG concentrations may be due to the greater levels of lipoprotein lipase in women than men (Kashyap et al. 1983; Weintraub et al. 1987). Lipoprotein lipase stimulates the clearance of 
postprandial TAG. In the present study, the study cohort was composed of both men and women, therefore sex was included as an independent factor in the statistical model used to analyse the data. Neither fasting nor postprandial plasma TAG concentration was significantly affected by sex; however, both fasting and postprandial CM-TAG concentrations were significantly greater in the male subjects, as illustrated in Fig. 1. The males had higher CM-TAG concentrations than the females, while the HF meal generated a greater postprandial lipaemic response than the LF meal, in both groups.

The pattern of postprandial NEFA response was similar to that previously reported (Gibney \& Daly, 1994; Murphy et al. 1995), that is, an initial decline followed by a gradual rise, but there were no significant differences between the $\mathrm{HF}$ and LF meals. The postprandial insulin response was not affected by the level of fat provided in the test meals. Murphy et al. (1995) also showed no significant effect of 20, 40 or $80 \mathrm{~g}$ fat on postprandial insulinaemia. However, Dubois et al. (1998) demonstrated that the insulin AUC was significantly greater following a $50 \mathrm{~g}$ fat meal, compared with a $15 \mathrm{~g}$ fat meal. In the present study, the postprandial GIP response was not significantly different between meals, although plasma GIP concentrations were elevated for a longer time following the HF meal. There is some evidence to suggest that the postprandial plasma GIP response to fat is dose-dependent. Murphy et al. (1995) demonstrated that the postprandial GIP response was significantly greater following an $80 \mathrm{~g}$ fat meal, but there was no significant difference between the 20 and $40 \mathrm{~g}$ fat doses.

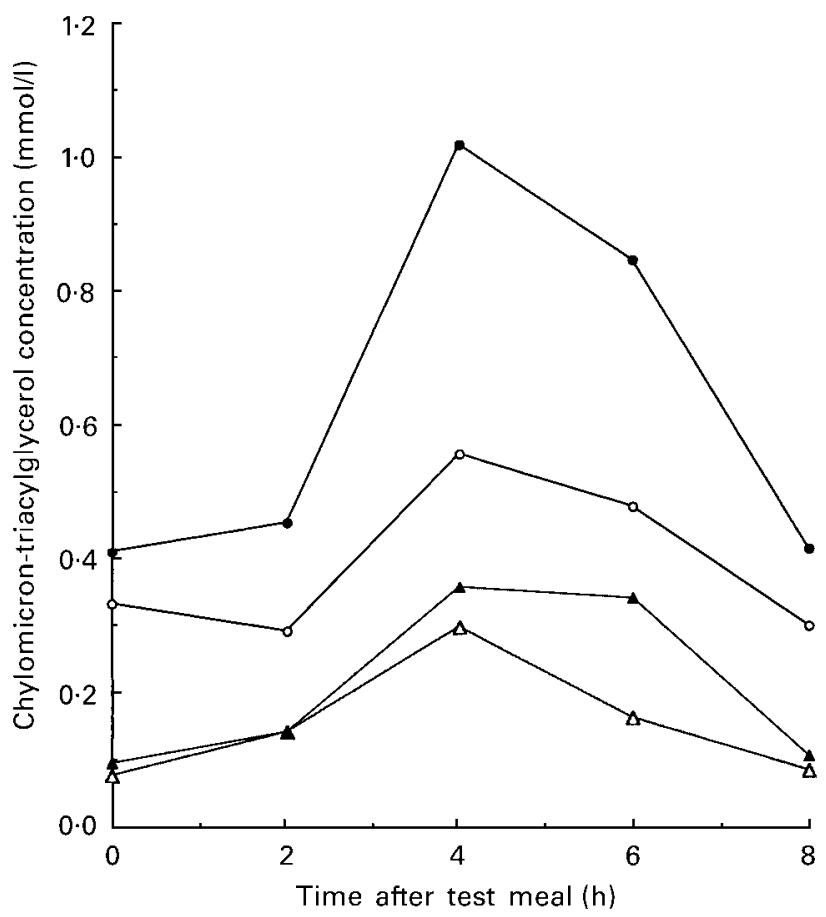

Fig. 1. Postprandial chylomicron-triacylglycerol concentrations following high-fat (HF) and low-fat (LF) test meals in male and female subjects. (O), LF meal, males; $(\bullet)$, HF meal, males; $(\triangle)$, LF meal, females; $(\boldsymbol{\Lambda})$, HF meal, females. Values are means for four subjects. For details of meals and procedures, see p. 26.
Regression analysis was completed to identify the significant determinants of GIP AUC; this showed that fasting GIP concentrations and between-subject variation were the most important factors, and CM-TAG AUC to a lesser extent. Clearly non-dietary factors play a greater role in determining the GIP response to fat ingestion than does the dose of fat ingested. Although chronic high-fat diets have been found to lead to an increased postprandial sensitivity in GIP release in response to oral glucose loads, these findings would not support the concept that chronic rather than acute fat intake influences fasting plasma GIP (Knapper et al. 1996). The effect of fat intake on plasma GIP response and the significance of postprandial GIP response to CM and NEFA metabolism is poorly understood and warrants investigation.

In conclusion, low doses of fat $(0.2 \mathrm{~g} / \mathrm{kg})$ were found to elicit a weak and short-lived postprandial TAG response and this would indicate that for the majority of eating occasions, where fat intake is known to be at or about this level, some degree of lipaemia will be encountered. This has implications in the area of periodicity of eating and its influence on plasma cholesterol through activation of reverse cholesterol transport via postprandial inter-lipoprotein lipid exchange (Mann, 1997).

\section{Acknowledgements}

We wish to thank all those who volunteered to participate in this study. Farideh Shishehbor kindly acknowledges the Islamic Republic of Iran Ministries of Health and Education for funding. Research costs were kindly covered by Nutriscan Limited, a non-profit campus company of Trinity College Dublin.

\section{References}

Alam MJ, Kerr JI, Cormican K \& Buchanan KD (1992) Gastric inhibitory polypeptide (GIP) response in diabetes using a highly specific antiserum. Diabetic Medicine 9, 542545 .

Bonanome A \& Grundy SM (1989) Intestinal absorption of stearic acid after consumption of high fat meals in humans. Journal of Nutrition 119, 1556-1560.

Chen YDI, Skowronsli R, Coulston AM, Pietarinen J, Hollenbeck CB \& Reaven GM (1992) Effect of acute variations in dietary fat and carbohydrate intake on retinyl ester content of intestinally derived lipoproteins. Journal of Clinical Endocrinology and Metabolism 74, 28-32.

Cohen JC, Noakes TD \& Benade AJS (1988) Serum triglyceride responses to fatty meals: effect of meal fat content. American Journal of Clinical Nutrition 47, 825-827.

Cohn JS, McNamara JR, Cohn SD, Ordovas JM \& Schaefer EJ (1988a) Plasma apolipoprotein changes in the triglyceride-rich lipoprotein fraction of human subjects fed a fat-rich meal. Journal of Lipid Research 29, 925-936.

Cohn JS, McNamara JR, Cohn SD, Ordovas JM \& Schaefer EJ (1988b) Postprandial plasma lipoprotein changes in human subjects of different ages. Journal of Lipid Research 29, 469-479.

De Castro JM (1987) Circadian rhythms of the spontaneous meal pattern, macronutrient intake, and mood of humans. Physiology and Behavior 40, 437-466.

Dubois C, Armand M, Azais-Braesco V, Portugal H, Pauli A-M, 
Bernard P-M, Latge C, Lafont H, Borel P \& Lairon D (1994) Effects of moderate amounts of emulsified dietary fat on postprandial lipemia and lipoproteins in normolipidemic adults. American Journal of Clinical Nutrition 60, 374-382.

Dubois C, Beaumier G, Juhel C, Armand M, Portugal H, Pauli A-M, Borel P, Latge C \& Lairon D (1998) Effects of graded amounts $(0-50 \mathrm{~g})$ of dietary fat on postprandial lipemia and lipoproteins in normolipidemic adults. American Journal of Clinical Nutrition 67, 31-38.

Gibney MJ \& Daly E (1994) The incorporation of $n-3$ polyunsaturated fatty acids into plasma lipid and lipoprotein fractions in the postprandial phase in healthy volunteers. European Journal of Clinical Nutrition 48, 866-872.

Groot PHE \& Scheek LM (1984) Effects of fat ingestion on high density lipoprotein profiles in human sera. Journal of Lipid Research 25, 684-692.

Grundy SM \& Mok HYI (1976) Chylomicron clearance in normal and hyperlipidemic man. Metabolism 25, 1225-1239.

Jeppesen J, Chen Y-DI, Zhou M-Y, Wang T \& Reaven GM (1995) Effect of variations in oral fat and carbohydrate load on postprandial lipemia. American Journal of Clinical Nutrition 62, 1201-1205.

Kashyap ML, Barnhart RL, Srivastava LS, Perisutti G, Allen C, Hogg E, Glueck CJ \& Jackson RL (1983) Alimentary lipemia: plasma high-density lipoproteins and apolipoproteins CII and CIII in healthy subjects. American Journal of Clinical Nutrition 37, 233-243.

Knapper JME, Morgan LM \& Fletcher JM (1996) Nutrientinduced secretion and metabolic effects of glucose-dependent insulinotropic polypeptide and glucagon-like peptide-I. Proceedings of the Nutrition Society 55, 291-305.

Krasinski SD, Cohn JS, Schaefer EJ \& Russell RM (1990) Postprandial plasma retinyl ester response is greater in older subjects compared with younger subjects. Journal of Clinical Investigation 85, 883-892.

Mann J (1997) Meal frequency and plasma lipids and lipoprotein. British Journal of Nutrition 77, Suppl. 1, S83-S90.

Mathews JNS, Altman DG, Campbell MJ \& Royston P (1990) Analysis of serial measurements in medical research. British Medical Journal 300, 230-235.

Murphy MC, Isherwood SG, Sethi S, Gould BJ, Wright JW,
Knapper JA \& Williams CM (1995) Postprandial lipid and hormone responses to meals of varying fat contents: modulatory role of lipoprotein lipase? European Journal of Clinical Nutrition 49, 579-588.

O'Flaherty L \& Gibney MJ (1994) The effect of very-low, moderate- and high-fat snacks on postprandial reverse cholesterol transport in healthy volunteers. Proceedings of the Nutrition Society 53, 124A.

Redgrave TG \& Carlson LA (1979) Changes in plasma very low density and low density lipoprotein content, composition, and size after a fatty meal in normo- and hypertriglyceridemic man. Journal of Lipid Research 20, 217-229.

Rifai N, Merrill JR \& Holly RG (1990) Postprandial effect of a high fat meal on plasma lipid, lipoprotein cholesterol and apolipoprotein measurements. Annals of Clinical Biochemistry 27, 489-493.

Roche HM \& Gibney MJ (1995) Postprandial triacylglyerolaemia-nutritional implications. Progress in Lipid Research 34, 249-266.

Roche HM \& Gibney MJ (1996) Postprandial triacylglycerolaemia: the effect of low-fat dietary treatment with and without fish oil supplementation. European Journal of Clinical Nutrition 50, 617-624.

Roche HM, Zampelas A, Jackson KG, Williams CM \& Gibney MJ (1998) The effect of test meal monounsaturated : saturated fatty acid ratio on postprandial lipid metabolism. British Journal of Nutrition 79, 419-424.

Weintraub MS, Eisenberg S \& Breslow JL (1987) Dietary fat clearance in normal subjects is regulated by genetic variation in apolipoprotein E. Journal of Clinical Investigation 80, $1571-1577$

Zampelas A, Murphy M, Morgan LM \& Williams CM (1994a) Postprandial lipoprotein lipase, insulin and gastric inhibitory polypeptide responses to test meals of different fatty acid composition: comparison of saturated, $n-6$ and $n-3$ polyunsaturated fatty acids. European Journal of Clinical Nutrition 48, 849-858.

Zampelas A, Peel AS, Gould BJ \& Williams CM (1994b) Polyunsaturated fatty acids of the $n-6$ and $n-3$ series: effects on postprandial lipid and lipoprotein levels in healthy men. European Journal of Clinical Nutrition 48, 842-848. 